\title{
La réception et l'utilisation des Aventures de Télémaque en Serbie
}

Biljana Stikić

\section{CpenEdition}

Journals

Édition électronique

URL : https://journals.openedition.org/dhfles/1342

DOI : $10.4000 /$ dhfles. 1342

ISSN : 2221-4038

Éditeur

Société Internationale pour l'Histoire du Français Langue Étrangère ou Seconde

Édition imprimée

Date de publication : 1 décembre 2003

Pagination : 65-76

ISSN : 0992-7654

Référence électronique

Biljana Stikić, "La réception et l'utilisation des Aventures de Télémaque en Serbie », Documents pour I'histoire du français langue étrangère ou seconde [En ligne], 31 | 2003, mis en ligne le 01 janvier 2012, consulté le 20 juillet 2022. URL : http://journals.openedition.org/dhfles/1342 ; DOI : https://doi.org/ $10.4000 /$ dhfles. 1342

Ce document a été généré automatiquement le 20 juillet 2022.

Tous droits réservés 


\title{
La réception et l'utilisation des Aventures de Télémaque en Serbie
}

\author{
Biljana Stikić
}

\section{La pénétration de la culture française et l'arrivée de Télémaque}

C'est dans la seconde moitié du XVIII ${ }^{e}$ siècle que l'on peut remarquer la présence et l'expansion de la culture française chez les Serbes. D'une part, la langue française ayant alors conquis les hautes classes sociales de toute l'Europe civilisée fait partie d'une bonne éducation caractérisée par de belles manières. D'autre part, à l'âge des Lumières la littérature française exerce une grande influence sur l'évolution des littératures européennes et autres (Polovina $1964: 7$ ). À cette époque-là, les érudits et les enthousiastes d'origine serbe commencèrent à entreprendre un travail, une sorte de réveil du peuple serbe concernant la langue littéraire commune, la science et, enfin, la littérature. C'est sans doute un aspect de ce siècle des Lumières qui a provoqué l'engagement de ces gens aussi brillants ; l'esprit imprégné par les idées venues de la philosophie du rationalisme qui annonçait l'aube des temps modernes donna lieu à un renouveau intellectuel et littéraire au niveau national. De ce point de vue on pourra comprendre la réception des oeuvres de Fénelon par les Serbes et en Serbie, notamment de son chef-d'oeuvre, les Aventures de Télémaque, qui a d'ailleurs été l'un des romans français les plus populaires chez les Serbes à la fin du XVIII eet au début du XIX ${ }^{e}$ siècles (Gavrilović 1968: 253). Tandis que la majorité des Serbes vivait inculte et soumise dans la partie occidentale de l'empire ottoman, un bon nombre de Serbes habitaient au XVIII ${ }^{e}$ siècle la province méridionale de l'Autriche. On trouve parmi eux ceux qui, appartenant aux diverses classes sociales, travaillaient ou faisaient leurs études dans de grands centres culturels et universitaires, tels que Vienne, Leipzig ou Halle. Ils y commencèrent à apprendre la langue et les éléments de la culture française lorsque la gallomanie avait atteint son sommet transformant les manières de se 
comporter et déterminant le style de vie de toutes les classes sociales (Polovina 1964 : 8-10).

C'est à cette époque que les Serbes prirent connaissance, d'abord en français et un peu en allemand, des nombreuses tentations de Télémaque et des sages conseils de Mentor, au fait la déesse Minerve, en réalité Fénelon. Il faut signaler que les habitants de la province autrichienne méridionale pouvaient se procurer des œuvres littéraires écrites en langue française aussi dans quelques petites villes de cette province. Ainsi, Emanuel Jankovicavait ouvert en 1790 la librairie francoallemande à Novi Sad. Parmi de nombreux titres de livres français cités dans le catalogue, on trouve aussi celui des Aventures de Télémaque(Kostić 1929 : 67).

\section{Le rôle de Dositej Obradović}

3 C'est Dositej Obradović, célèbre écrivain serbe du XVIII siècle, qui va'jouer un rôle fort important dans la propagation des idées de Fénelon chez les Serbes. Après sa vie monacale, Dositej Obradović devient instituteur: il va visiter les plus grandes villes de l'Europe, de Londres, Paris, Venise, Bologne, Florence jusqu'à Moscou, Constantinople et les îles méditerranéennes. C'est lui qui était un véritable représentant serbe de la nouvelle classe de gens qui avait imposé un nouveau type, celui de l'homme de lettres. Défendant la raison, la nature, le déisme et le pacifisme dans ses ouvrages, Dositej exercera, presque toute sa vie, un métier ingrat et difficile. Quelques années avant sa mort, il revient en Serbie où il devient le premier ministre de l'éducation nationale (Obradović 1982 : 234-242).

4 Pendant son séjour à Vienne où il donne des leçons particulières d'italien et de grec, il apprend le français chez l'un des nombreux gouverneurs maittres de danse français en Autriche. Courtois, érudit avant tout, ce Français offrait à Dositej des livres français choisis, parmi lesquels l'ouvrage déjà célèbre de Fénelon qui lui valut la disgrâce, et qui exerça en outre une grande influence sur la réflexion du premier. Si l'attitude critique de Dositej tire son origine des ouvrages de Descartes, Leibniz et Locke, ses réflexions sur la modération, la prudence et la moralité viennent des Aventures de Télémaque. Simultanément, Dositej recommandait aux érudits serbes de traduire ce roman estimant que c'était l'un des meilleurs outils pour rendre la culture française plus proche des Serbes (Obradović 1911: 24). C'est de cette manière - à une époque très importante pour la renaissance culturelle d'un peuple - que les exemples de moralité du fils d'Ulysse parvinrent par une porte grande ouverte.

Il faut souligner que l'intérêt des savants serbes pour la littérature française était alors étroitement lié aux ouvrages reflétant l'esprit de rationalisme. Cependant, avant Télémaque, les Serbes eurent l'occasion de connaître un petit nombre d'œuvres françaises appartenant à la littérature didactique, telles que Sur le goût de la solide gloire et de la véritable grandeur de Charles Rollin, le Magasin des enfants ou Dialogues entre une sage gouvernante et ses élèves de Marie Leprince de Beaumont, Agar dans le désert de Stéphanie Félicite du Crest de Saint-Aubin et enfin l'oeuvre de Pierre Blanchard Le Plutarque de la jeunesse ou abrégé des vies des plus grands hommes de toutes les nations (Gavrilović 1997 : 35). L'insistance de Dositej à l'égard de la traduction de Télémaque en langue serbe, qui va toucher un public plus large, va permettre quelques années plus tard la naissance de la première grammaire française à l'usage des Serbes, grammaire rédigée par Joakim Vujić et publiée en 1805 à Budapest (Vujić). 


\section{Télémaquechez les insurgés serbes}

Après le premier soulèvement contre les Ottomans en 1804, une délégation de Serbie, envoyée à Vienne, y trouva Stefan Živković,étudiant en médecine à la fin de ses études, plus tard homme politique et écrivain, et l'invita à aider la mis Joakim Vujić, et l'invita à aider la mission culturelle en Serbie. Comme Joakim Vujić, il avait été formé à l'enseignement secondaire en partie à Bratislava où il faisait ses premiers pas en langue française. Živkovićapporta en Serbie une édition parisienne des Aventures de Télémaque. Durant quatre années, entre 1809 et 1813 , il a séjourné dans des camps militaires où lisant ce roman il approfondissait sa connaissance du français, il le traduisit également, et l'expliqua aux insurgés serbes. Rassemblés autour de lui, ils l'écoutaient attentivement, le priant de lire et d'interpréter encore quelques aventures de Télémaque et de son précepteur, et de traduire ce roman en bloc. Peu à peu, il y réussit. En 1814, il s'installa à Vienne où il fit imprimer et publier sa traduction de ce chef d'œuvre de Fénelon (Kovijanić 1955). Un grand nombre d'abonnés témoignent du succès et d'une bonne réception de la part des Serbes intéressés à l'apprentissage de la culture française (Fénelon 1814 : 5-16). Immédiatement après la publication de cet ouvrage, des bruits circulaient que Stefan Živković avait "pris» la traduction de Dositej Obradović. Conscient de l'importance de son projet, le premier, étant fâché, répondit prudemment : «Il faut laisser les gens penser que Dositej a traduit ce roman. Cela nous aidera à vendre le reste des exemplaires. Nous leur démontrerons plus tard que, après Dositej, il y a encore de bons interprètes » (Ristić1956: 18). Rappelons aussi que la traduction littérale du mot Télémaque ou Telemachos (en grec) signifie celui qui lutte au loin (Vujaklija 1991 : 875). Ainsi la traduction serbe de Télémaque et sa publication avaient-elles été marquées par un étrange concours de circonstances - la lutte des insurgés serbes.

\section{Destin de la traduction serbe}

7 Excepté son rôle dans le cadre de la littérature, cette traduction avait paru au moment où l'on remarque le début de la création de la langue serbe littéraire, c'est-à-dire lorsque la pénétration des gallicismes dans le serbe battait son plein. Après cette traduction intégrale, personne n'a plus traduit en langue serbe le roman de Fénelon. Plus tard, à la fin du XIX ${ }^{e}$ siècle, un instituteur allait faire publier la version abrégée de cette traduction pour la consacrer aux nouvelles générations de jeunes gens émerveillées par les aventures de Télémaque et la mythologie grecque (Fénelon 1897). La correspondance entre les érudits serbes de cette époque nous montre que Stefan Živković était surnommé Télémaque ce qui s'est maintenu en littérature serbe jusqu'à nos jours (Ristić 1956 : 3). Lorsque la langue française devient matière scolaire dans la principauté de Serbie - il s'agit des années Quarante du XIX ${ }^{e}$ siècle - on ne trouve aucun ouvrage de Fénelon; la préférence est donnée à Chateaubriand, Buffon et Montesquieu en ce qui concerne les lectures. En 1852, c'est Bélisaire de Marmontel auquel sont ajoutées les explications de grammaire et le vocabulaire français-serbe, consacré aux étudiants de la Grande école qui deviendra plus tard l'Université de Belgrade (Polovina 1964 : 108-109). Vers la fin du XIX ${ }^{e}$ siècle, quand la tendance dans l'enseignement du français langue étrangère favorisait la lecture, Télémaque devient de nouveau 
intéressant en Serbie, et on recommande sa lecture et son étude en langue française à côté des classiques français et des écrivains moins connus (Polovina 1964 : 108-109).

Durant la période d'entre-deux-guerres, Télémaque n'apparait dans l'enseignement du français ni sous forme de manuel de français ni en tant qu'oeuvre recommandée pour la lecture. Il faut noter cependant que l'Éducation des filles, un des livres les plus populaires chez les Serbes au XIX ${ }^{\mathrm{e}}$ siècle (Gabrilović 1997: 39), trouve sa place dans les programmes pour les écoles normales. Les futures institutrices qui apprenaient le français en tant que première langue étrangère étaient obligées d'étudier cette oeuvre et de la présenter par écrit et oralement pendant les séminaires. Pour ce qui concerne les lectures à caractère didactique, ce sont les écrivains français modernes de l'époque qui prennent la première place durant l'entre-deux-guerres. Dans d'autres établissements d'enseignement secondaire où l'on apprenait le français, on lisait et étudiait, selon l'âge des élèves, les classiques français ainsi que Voltaire, Malot, Daudet... Signalons enfin que, entre 1928 et 1937, Radio Belgrade a organisé des cours de français consacrés à un public plu large (Stikić 2002 : 31). Au milieu des exercices d'orthographe, de grammaire, de prononciation et de conversation en français standard, on pouvait aussi entendre des morceaux littéraires choisis, parmi lesquels ceux de Fénelon (Radio Beograd 1936 : 11).

La période d'enseignement français en Serbie durant les années qui ont suivi la Seconde guerre mondiale et jusqu'à nos jours n'a pas été l'objet de profondes recherches scientifiques. Il est probable que les œuvres de Fénelon, notamment son Télémaque, n'étaient pas intéressantes à cette période qui est tournée vers l'avenir, vers divers champs scientifiques et sociaux qui supportaient la création de nouvelles méthodes d'acquisition en Europe et, par reflet, en Serbie. Il s'agit aussi de nouveaux matériaux pédagogiques. Aujourd'hui, Fénelon et les Aventures de Télémaque ne sont pas oubliés : ils restent liés à l'apprentissage de la langue et de la culture françaises dans les études supérieures et doctorales, ainsi que dans les recherches en littérature française (Krstić 1999).

\section{BIBLIOGRAPHIE}

\section{Bibliographie}

FÉNELON (1814), Prikljčenija Telemaka sina Ulisova, Vijena, s francuzskoga prevedena Stefanom Živkovicem.

-----(1897), Telemakovi dozivljaji, Osek, prevod D. Djuric.

GABRILOVIĆ, Nikola (1968), Francuski jezik kod Srba u juznoj Ugarskoj krajem 18. i početkom 19. Veka i srpsku knjizevnost krajem 18. i početkom 19. veka, Novi Sad, Rad vojovdjanskih muzeja 3.

------(1997), Srbi i Francuzi : Francuski uticaji na Srbe i srpsku knjizevnost krajem 18. i početkom 19. veka, Beograd. 
KOVIJANIĆ, Risto (1955), « Skolovanije Stefana Živkovica Telemaka », Zbornik Matice srpske za khnizevnost i jezik 3, Novi Sad, 175-177.

KOSTIĆ, Mita (1929), « Prve pojave francuske kulture u srpskom društvu », Glasnik istoriskog društva 2, 1 Novi Sad, 66-72.

KRSTIĆ, Nenad (1999), Francuska knjizevnost u srpskim prevodina 1776-1843, Novi Sad.

OBRADOVIĆ, Dositej (1911), Dela Dositeja Obradovića, Beograd, 5. Izdanje.

------ (1982), Zivot i priključenija. Pismo Haralampiju, Beograd, Nolit.

POLOVINA, Pera (1964), Uddzbenici francuskog jezika kod Srba do 1914. godine, Beograd, Drustvo za strane jezike i knjizevnosti.

RADIO BEOGRAD (1936), « Časovi francuskog jezika », Nedeljna revija 43, 11.

RISTIĆ, Milan (1956), Stefan Živkovic Telemak, politicar i knijzevnik obnovljeneSrbije 1780-1831, Beograd, Prosveta.

STIKIĆ, Biljana (2002), « Radio et enseignement : premiers pas, de 1924 à 1934 », Le français dans le monde $321,31-32$.

VUJAKLIJA, Milan (1991), Leksikon stranih reči i izraza, Beograd, Prosveta.

VUJIĆ, Joakim ( 1805), Rukovodstvo k francuzstjej grammatice vo upotreblenije slaveno-serbskija junost sočinjeno, Budim.

\section{RÉSUMÉS}

Le grand écrivain serbe du XVIII ${ }^{\mathrm{e}}$ siècle, Dositej Obradović, a eu un rôle important dans la propagation du chef-d'oeuvre de Fénelon. Après quelques essais de traduction et après la parution de la première grammaire française à l'usage des Serbes en 1805, Stefan Živković, surnommé plus tard Télémaque, quitte Vienne pour la Serbie où il traduit ce roman qu'il lit et explique aux insurgés serbes participant au soulèvement contre l'empire ottoman. Ce roman n'a jamais été si populaire chez les Serbes qu'au XVIII et au début du XIX ${ }^{e}$ siècle, mais les réflexions pédagogiques de Fénelon ont été longtemps au cœur de la formation en langue française des futurs instituteurs.

The great Serbian writer of the $18^{\text {th }}$ century, Obradović, played an important role in promoting this masterpiece of Fénelon. After a few attempts at translating the work, and the publishing of the first French grammar intended for Serbs in 1805, Stefan Zivković, later named Télémaque, leaves Vienna and departs for Serbia where after translating this novel, reads and interprets it to the insurgents against the Ottoman empire. This work was never as popular with Serbs as it was in the $18^{\text {th }}$ century and in the beginning of the $19 \mathrm{th}$, but Fenelon's thought remained at the core of French language teaching in pedagogical schools for a long time.

\section{INDEX}

Keywords : Fénelon, Serbia, Telemachus, XVIIIth century

Mots-clés : Aventures de Télémaque, Fénelon, Obradović (Dositej), Serbie, Télémaque, XVIIIe siècle, Živković (Stefan) 
AUTEUR

BILJANA STIKIĆ

Lycée Svetozar Mileti de Novi Sad 